\title{
Kajian Tanah Ekspansif, Jalan Akses Jembatan Suramadu Sisi Madura
}

\author{
Chomaedhi, M. Khoiri \& Machsus \\ Staft Pengajar Program Studi D-III Teknik Sipil FTSP \\ email:chomaedhi@ce.its.ac.id; mkhoiri@ce.its.ac.id; machsus@ce.its.ac.id
}

\begin{abstract}
ABSTRAK
Kajian tanah ekspansif pada ruas jalan akses jembatan Suramadu sisi Madura ini dilakukan guna mengetahui sifat dan karakteristik tanah dasar pada lokasi ruas jalan tersebut. Ruas jalan akses sisi Madura yang dimaksud dalam kajian ini adalah mulai Sta 0+050 s/d Sta $6+000$. Pada lokasi tersebut kondisi permukaan tanah bervariasi antara dataran rendah dan perbukitan, sehingga jalan akses tersebut pada daerah dataran rendah dibuat diatas timbunan, sedangkan pada dataran tinggi jalan berada pada daerah galian. Pada penenelitian terdahulu disebutkan jenis tanah pada lokasi tersebut banyak mengandung monmorilinite, sehingga dikhawatirkan berpotensi terjadi kembang susut pada tanah lokasi tersebut. Dan hal tersebut mempunyai konsekuensi terhadap bentuk perkuatan konstruksi jalan akses tersebut. Kajian ini bermaksud meneliti kembali sejauh mana potensi kembang susut pada tanah tersebut, sehingga diharapkan dapat menjadi pertimbangan untuk membuat desain jalan yang lebih hemat. Dari kajian yang telah dilakukan disimpulkan bahwa unsur monmorilonite yang ada pada tanah tersebut telah terkomposit dengan material lain (tersementasi) dan menjadi bersifat material lain, sehingga sifat kembangsusutnya relatif kecil. Dan sifat kembang susut yang relatif kecil tersebut telah juga terbukti di laboratorium dengan tes swelling.
\end{abstract}

Kata Kunci: Kajian Tanah, Tanah Ekspansif, Jembatan Suramadu

\section{PENDAHULUAN}

Kajian tanah ruas jalan akses jembatan Suramadu sisi Madura Proyek Pembangunan Jembatan Suramadu (PPJS) ini dilakukan guna mengetahui sifat dan karakteristik tanah dasar pada lokasi ruas jalan tersebut. Ruas jalan akses sisi Madura yang dimaksud dalam penyelidikan tanah ini adalah mulai Sta 0+050 s/d Sta 6+000.

Pada ruas tersebut sebagian badan jalan berada daerah galian (cutting) yaitu mulai Sta 0+050 s/d Sta 1+700 dan sebagian badan jalan merupakan timbunan yaitu mulai Sta $1+700$ s/d Sta 6+000. Selanjutnya penyelidikan ini lebih difokuskan pada ruas jalan yang berada di daerah galian yaitu pada ruas mulai Sta 0+050 s/d Sta 1+700. Hal tersebut disebabkan karena pada daerah tersebut ditengarai tanah dasarnya bersifat ekspansif, sehingga perlu dikaji lebih lanjut mengenai konstruksi badan jalan dan konstruksi perkuatan lerengnya.

Kajian tanah pada ruas jalan akses jembatan Suramadu sisi Madura Proyek Pembangunan Jembatan Suramadu (PPJS) ini bertujuan untuk mengetahui jenis dan karakteristik tanah dasar pada ruas jalan akses jembatan Suramadu sisi Madura mulai Sta 0+050 s/d Sta 6+000. Mendapatkan rekomendasi mengenai konstruksi badan jalan dan konstruksi perkuatan lereng khususnya pada badan jalan yang berada pada daerah galian.

\section{TINJAUAN PUSTAKA}

Tanah ekspansif adalah jenis tanah yang mudah mengalami perubahan volume akibat adanya perubahan kadar air dalam pori-pori tanah. Bila kadar air dalam pori tanah meningkat volume tanah akan mengembang, dan bila kadar air tanah berkurang sebaliknya tanah akan menyusut.

Hal tersebut disebabkan oleh sifat dasar molekul jenis tanah yang membentuk dipoldipol sehingga mempunyai kemampuan untuk mengikat molekul air yang sangat besar. Jenis tanah yang mempunyai molekul dengan sifat tersebut umumnya adalah jenis tanah lempung dengan salah satu partikel 
dasarnya yang bersifat demikian adalah jenis monmorilonite.

Di lapangan, akibat adanya kembang susut pada tanah ekspansif tersebut, maka menyebabkan kerusakan struktur bangunan yang berada diatasnya misalnya jalan, lantai rumah dll. Sehingga diperlukan disain khusus pada dasar struktur bangunan tersebut, agar terhindar dari kerusakan yang mungkin ditimbulkan oleh tanah ekspansif tersebut.

Untuk mengetahui potensi kembang-susut suatu jenis tanah, metode umum yang digunakan adalah dengan dilakukan uji laboratorium Indeks Plastisitas untuk diplot pada Placticity Chart, dicari tingkat keaktifannya, tes tekanan kembang susut, dan uji kandungan mineral (misal dengan $X$ Ray Difraction).

Dari penyelidikan tersebut diatas ditentukan apakah tanah pada suatu lokasi merupakan tanah ekspansif atau tidak. Dan hal tersebut akan menentukan bentuk konstruksi yang berada diatasnya, agar tidak terjadi kerusakan yang diakibatkan oleh tanah ekspansif.

\section{METODE PENELITIAN}

\subsection{Studi Pendahuluan}

Pada tahap studi pendahuluan ini dilakukan studi terhadap data yang telah ada yaitu data Laporan Kajian Tanah Ekspansif Ruas Jalan Akses Sisi Madura yang dibuat oleh Pusat Penelitian dan Pengembangan (Puslitbang) Bandung Departemen Permukiman dan Prasarana Wilayah. Selain itu dilakukan pula penggalian informasi lainnya yang didapatkan dari diskusi dengan pihak-pihak penyelenggara Proyek Pembangunan Jembatan Suramadu (PPJS).

\subsection{Penyelidikan Lapangan}

Penyelidikan lapangan ini meliputi:

- Survey lapangan

- Pengambilan sample lapangan dengan Tes Pit

- Tes CBR lapangan dengan DCPT

\subsection{Penyelidikan Laboratorium}

Penyelidikan laboratorium ini meliputi:

- Test CBR Laboratorium (SNI 03-17441989)
- Tes 'Swelling' (SNI 03-1744-1989)

- Tes Batas Cair (SNI 03-1967-1990)

- Tes Batas Plastis (SNI 03-1966-1990)

- Tes gradasi butiran (Tes Ayakan dan Hydrometer) (SNI 03-3423-1994)

- Tes Triaksial UU ( SNI 03-4813-1998)

\subsection{Kesimpulan dan saran}

Pada tahap ini dilakukan analisa terhadap data lapangan, laboratorium, dan data dari laporan terdahulu, untuk kemudian diambil kesimpulan dan rekomendasi konstruksi badan jalan.

\section{HASIL DAN PEMBAHASAN \\ 4.1. Studi Pendahuluan}

Dari hasil laporan studi sebelumnya (Puslitbang Jalan, 2004) diketahui hal-hal sebagai berikut :

a. Stratigrafi. Stratigrafi daerah sisi Madura dibagi menjadi 4 (empat) satuan batuan utama, yaitu: Top Soil (tanah permukaan), Satuan Aluvium (Qa), Satuan Batupasir Gampingan, Satuan Batugamping Terumbu, Satuan Serpih

b. Sebaran horisontal batuan penyusun ruas jalan. Sebaran horizontal batuan penyusun ruas jalan akses sisi Madura (Sta. 0+000 - Sta.11+500) adalah sebagai berikut :

- Sta. 0+000 - Sta. 0+875 Serpih (daerah cut/galian)

- Sta. 0+875 - Sta. 1+200 Batugamping Terumbu (daerah cut/galian)

- Sta. 1+200 - Sta. 1+750 Batupasir Gampingan (daerah cut/galian)

- Sta. 1+750 - Sta. 3+100 Top Soil

- Sta. 3+100 - Sta. 11+500 Material Timbunan

c. Pengujian tingkat keaktifan fraksi tanah pada permukaan (keaktifan thd kembang susut tanah). Dengan menggunakan rumusan Skempton (1953), dinyatakan oleh Puslitbang (2004) bahwa jalan akses sisi Madura pada Sta. 0+000 - Sta. 0+500 berada dalam rentang keaktifan normal, sedangkan di sekitar Sta. 0+735 menunjukkan sifat yang aktif.

d. Pengujian X-Ray Diffraction. Pengujian XRay Diffraction menunjukkan bahwa deposit serpih pada Sta.0+000 tidak mengandung montmorillonite, sedangkan 
pengujian terhadap contoh serpih yang diambil dari Sta $0+500$ dan Sta 0+735 menunjukkan adanya kandungan montmorillonite yang signifikan, yaitu berturut-turut sebesar 21,25\% dan 22\%.

e. Pengeplotan LL dan PI pada Plasticity Chart USCS. Pengeplotan LL dan PI pada Plasticity Chart USCS yang dikembangkan oleh Casagrande (1932) menunjukkan bahwa deposit serpih pada daerah kajian seluruhnya berada di atas Garis A sehingga dapat digolongkan sebagai lempung inorganik dengan plastisitas tinggi atau ' $\mathrm{CH}$ '. Tanah golongan ini dipertimbangkan memiliki potensi bersifat ekspansif.

f. Klasifikasi tanah ekspansif dengan metode Chen (1965). Klasifikasi tanah ekspansif dengan menggunakan fraksi lolos saringan No. 200 dan batas cair (LL) dari pengujian batas-batas Atterberg serta nilai N SPT dikembangkan oleh Chen (1965) menunjukkan deposit serpih pada daerah akses Suramadu ini termasuk kedalam zona derajat ekspansi sangat tinggi.

g. Potensi pengembangan dengan metode Seed et al. (1962). Seed et al. (1962) mengembangkan korelasi antara potensi pengembangan dengan tingkat keaktifan dan fraksi lempung untuk suatu tanah remasan (remolded soil). Merujuk pada kriteria ini, deposit serpih daerah kajian sebagian besar memiliki potensi pengembangan yang tinggi s/d sangat tinggi.

h. Hubungan ekspansif soil dengan perencanaan tebal perkerasan. Untuk daerah kajian ini kehilangan tingkat pelayanan akibat perilaku tanah ekspansif yang harus diantisipasi pada perkerasan jalan adalah sebesar 0,63.

i. Stabilitas Lereng. Analisis stabilitas terhadap lereng cutting rencana yang terdapat pada gambar original design, menunjukkan bahwa lereng tersebut stabil (FOS $>1,5)$ dengan ketinggian cutting sekitar 6,0 meter.

\subsection{Penyelidikan Lapangan}

Dari pengamatan lapangan dan studi pendahuluan diketahui bahwa :

- Rencana Jalan akses Suramadu berada di daerah galian pada Sta 0+050 s/d 1+700.

- Rencana Jalan akses Suramadu berada di daerah dataran atau timbunan pada Sta $1+700 \mathrm{~s} / \mathrm{d} 11+500$

- Tanah dasar jalan umumnya merupakan tanah serpih yang relatif keras (dgn daya dukung tinggi) karena telah mengalami proses sementasi. Khusus pada Sta $0+375$ s/d ) 0+750 kekerasan batuan serpihnya relatif lebih rendah dari daerah lainnya.

- Pada lokasi setelah Sta 2+500 pada permukaan dijumpai tanah dasar berupa tanah lempung.

- Dijumpai lereng galian tanah di lapangan yang mulai Sta 0+050 s/d Sta 1+500 ada sejak tahun \pm 2003 dan telah terekspose selama \pm 2 tahun masih dalam kondisi stabil dan tidak mengalami kelongsoran. Juga terlihat adanya sedikit bukti gerusan-gerusan kecil akibat air hujan di permukaan lereng.

- Batuan dasar umumnya berupa limestone atau berupa clay stone (shale) yang telah tersementasi, berwarna coklat terang.

- Daerah lokasi akses Suramadu sisi Madura merupakan dataran tinggi, dan berbukit, sehingga kemungkinan banjir dapat dihindari dengan adanya saluran pematusan yang berfungsi baik.

- Penyelidikan CBR Lapangan dengan menggunakan DCPT menujukkan hasil yang berkisar antara 3\% s/d 62\% hanya untuk lapisan di permukaan setebal ratarata $10 \mathrm{~s} / \mathrm{d} 20 \mathrm{~cm}$. Lapisan di bagian bawahnya memberikan harga CBR yang jauh lebih besar karena sifat batuan yang keras (alat DCPT tidak dapat masuk lagi) jadi untuk perkerasan jalan, CBR dapat digunakan CBR batuan yang keras dengan catatan bahwa lapisan tanah tipis dipermukaan dibuang atau terlebih dahulu dipadatkan. 


\subsection{Penyelidikan Laboratorium}

Hasil Penyelidikan Laboratorium menunjukkan hal-hal, sebagai berikut:

1. Daya dukung tanah cukup tinggi, hai ini dapat ditunjukkan dari hasil tes CBR laboratorium dari contoh tanah dari Sta 0+500. Nilai CBR nya adalah:

- untuk sample yang tidak direndam (unsoaked), CBR $=37,4 \%$

- untuk sample yang direndam (soaked), CBR =19,8\%

Sebagai catatan, sample yang digunakan untuk uji CBR laboratorium di atas adalah sample tanah yang tidak asli, yaitu telah ditumbuk dan dipadatkan kembali sesuai kepadatan optimumnya. Jadi nilai CBR sesungguhnya di lapangan diperkirakan jauh lebih besar karena tanahnya masih asli dalam bentuk batuan serpih.

2. Hasil uji batas cair dan batas plastis dari fraksi tanah yang lolos ayakan No. 40 menunjukkan angka sebagai berikut:

- untuk Sample Sta 0+500

- Batas Cair, Liquid Limits (LL) = 51,5 $\%$

- Batas Plastis, Plastic Limits $(\mathrm{PL})=16,0 \%$

- Indek Plastis, Plasticity Indeks $(\mathrm{PI})=35,5 \%$

- untuk Sample Sta 1+500

- Batas Cair, Liquid Limits (LL) = $53,2 \%$

- Batas Plastis, Plastic Limits (PL) = $17,3 \%$

- Indek Plastis, Plasticity Indeks (PI) $=35,9 \%$

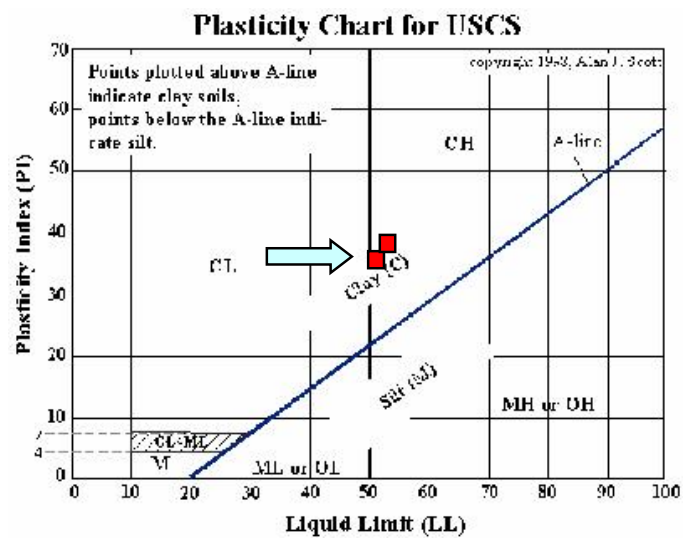

Gambar 1. Plasticity Chart for USCS
Pengeplotan pada Plasticity Chart USCS menunjukkan tanah berada pada perbatasan antara Clay low Plasticity (CL) dengan Clay High Plasticity (CH). Yang perlu menjadi catatan disini adalah bahwa nilai batas-2 plastisitas ini dominan disebabkan oleh mineral dasarnya yaitu lempung. Karena sampel untuk tes ini perlu dihancurkan terlebih dahulu dengan cara ditumbuk. Keadaan dilapangan kandungan lempung dalam sampel tanah ini telah saling terikat akibat proses sementasi alam, sehingga tanah asli yang sudah berbentuk batuan praktis lebih stabil.

3. Setelah direndam selama 24 jam, sample tanah tetap tegar, tidak hancur atau "mrotol". Pada tanah telah terjadi sementasi alam yang cukup kokoh, sehingga tanah yang berasal dari endapan tersebut telah menjadi batuan sedimen yang "irreverseable", tidak dapat kembali lagi menjadi tanah apabila direndam dalam air saja. Terbukti bahwa adanya air tidak dapat segera merubah batuan menjadi tanah kembali.

4. Sample yang berupa batuan atau serpih dapat menjadi fraksi yang lebih kecil, hanya bila dihancurkan secara mekanis (ditumbuk).

5. Potensi Swelling (berdasar Atterberg dan kandungan Clay) dari fraksi tanah yang telah ditumbuk adalah pada batas antara "sedang" dan "Tinggi".

$$
\begin{aligned}
\text { Tingkat Keaktifan } & =\text { IP } /(\% \text { partikel }<0,002 \mathrm{~mm}) \\
= & 35,5 \% / 17,7 \%=2,0 \\
= & 20 \%(\text { dari Tes Gradasi } \\
\text { Fraksi lempung } & \text { Butiran })
\end{aligned}
$$

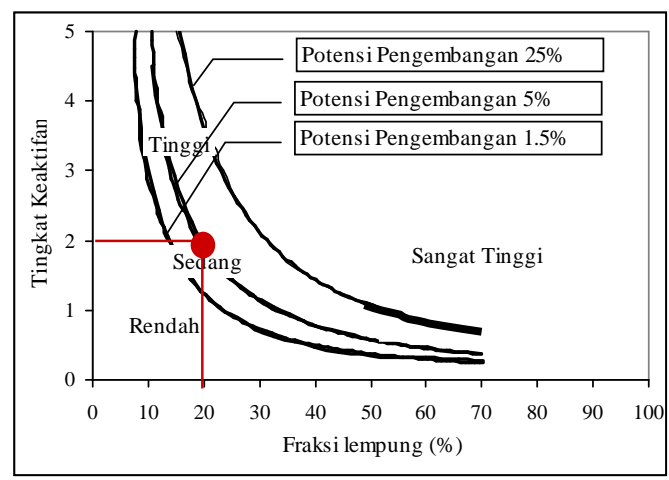

Gambar 2. Potensi Swelling Fraksi Tanah 


\section{ISSN.1907-753X}

Ini adalah potensi dari fraksi tanahnya. Pada kenyataan di lapangan, tanah asli yang sudah berbentuk batuan praktis tidak memiliki daya kembang-susut yang berarti.

6. Test Swelling dari fraksi tanah yang sudah ditumbuk menunjukkan bahwa tingkat swelling maksimum adalah sebesar 0,86\% (Rendah).

\section{KESIMPULAN}

Berdasarkan hasil dan pembahasan dapat ditarik kesimpulan sebagai berikut:

1. Tanah dasar dalam kondisi asli masih mempunyai daya dukung yang tinggi, walaupun telah terendam dengan air.

2. Walaupun pada fraksi tanahnya dijumpai kandungan mineral tanah dengan sifat kembang-susut yang besar (montmorillonite), pada kenyataannya di lapangan kandungan tersebut di banyak lokasi telah terikat secara tersementasi alamiah batuannya. Pengaruh air dan rendaman ternyata tidak menyebabkan tanah batuan tersebut menjadi bersifat "aktif" (kembang-susut). Jadi pada kasus ini, kembang-susut tanah bukanlah faktor yang dominan. Apalagi bila kemungkinan genangan oleh air hujan dapat dihindari.

3. Bila dibuat sistem drainase permukaan yang cukup baik, untuk melindungi tanah dasar lereng dan tanah dasar pondasi jalan (Subgrade), maka tidak perlu lagi dilakukan perbaikan tanah dasar. Tanah aslinya sudah cukup kuat dan stabil.

4. Perkerasan jalan pada section 0+050 s/d 1+700 dapat langsung dibangun di atas tanah asli tanpa adanya urugan perbaikan / pilihan. Pada bagian-bagian yang tidak langsung menumpu di atas batuan/serpih, tanah dasar yang relatif tipis dipermukaan supaya dipadatkan lebih dahulu.

5. Penanggulangan erosi permukaan pada daerah lereng cukup dengan gebalan rumput atau ditutupi jenis tanaman menjalar lainnya. Selain itu ditepi atas tebing pada bagian yang mendatar supaya dibuatkan saluran agar aliran air tidak mengalir melewati lereng dalam jumlah besar ("nggrojog”). Dasar saluran tersebut sebaiknya diberi lapisan batu kali atau pasangan bata yang diberi alas geomembrane untuk menjamin bahwa nantinya bila pada dinding saluran terjadi retak tidak akan terjadi rembesan air dari dalam saluran ke tanah di sekitarnya. Jadi air tidak akan mengganggu lereng galian.

\section{DAFTAR PUSTAKA}

Acuan yang digunakan dalam penyusunan paper ini adalah sebagai berikut :

Puslitbang Prasarana Jalan (2004), “Kajian tanah ekpansif pada jalan akses sisi Madura".

Laboratorium Uji Material Prodi D-3 Teknik Sipil FTSP-ITS (2005), “Laporan Penyelidikan Tanah Jalan Akses Jembatan Suramadu Sisi Madura”.

Mochtar I.B, et. all (2005), “Kajian Tanah Jalan Akses Jembatan Suramadu Sisi Madura, Studi Kasus : KM 0+050s/d KM $6+000 “$. 